\title{
Syndrome of Inappropriate Antidiuretic Hormone Secretion Associated with Amyotrophic Lateral Sclerosis in a Patient Developing Carbon Dioxide Narcosis
}

\author{
Yui Inoue ${ }^{1}$, Takaaki Murakami ${ }^{2}$, Takeshi Nakamura ${ }^{3}$, Kyohei Morita ${ }^{4}$, Daita Kaneda ${ }^{5}$, \\ Ichizo Nishino ${ }^{6}$, Tetsuya Hayashi ${ }^{1}$, Yuya Shinoto ${ }^{3}$, Tomonobu Hatoko ${ }^{2}$, Tomoko Kato ${ }^{2}$, \\ Shin Yonemitsu ${ }^{2}$, Seiji Muro ${ }^{2}$ and Shogo $\mathrm{Oki}^{2}$
}

\begin{abstract}
We report a rare case of syndrome of inappropriate antidiuretic hormone secretion (SIADH) associated with amyotrophic lateral sclerosis (ALS). A 69-year-old man was admitted to our hospital with sustained hyponatremia. Hyposmolality with elevated urinary osmolality and sodium excretion was observed, which indicated SIADH. The treatment for SIADH was challenging; the patient developed carbon dioxide narcosis, which led to the diagnosis of ALS. After the initiation of noninvasive positive-pressure ventilation, the patient's serum sodium concentration normalized and became stable. Thus, ALS should be recognized as a possible cause of SIADH in the clinical setting.
\end{abstract}

Key words: hyponatremia, SIADH, ALS, NPPV, $\mathrm{CO}_{2}$ narcosis, respiratory failure

(Intern Med 56: 797-803, 2017)

(DOI: 10.2169/internalmedicine.56.7033)

\section{Introduction}

Hyponatremia is the most commonly observed electrolyte abnormality in clinical practice $(1,2)$. Severe hyponatremia can be associated with a high mortality rate (3). The syndrome of inappropriate antidiuretic hormone secretion (SIADH) is the most common cause of hyponatremia and it is characterized by dilutional hyponatremia due to the excessive secretion of antidiuretic hormone (ADH) (4). SIADH is caused by various conditions, such as central nervous system disorders, malignant neoplasms, nonmalignant pulmonary diseases, invasive procedures, and adverse drug reactions. Amyotrophic lateral sclerosis (ALS) or motor neuron disease, which is a rare but clinically progressive and serious disease, is not a well-known cause of SIADH (5). Moreover, the underlying mechanism remains unclear (5).
We herein report a case of ALS-associated SIADH. The patient presented with disturbed consciousness due to carbon dioxide $\left(\mathrm{CO}_{2}\right)$ narcosis after sustained hyponatremia, which led to the diagnosis of ALS. Noninvasive positive-pressure ventilation (NPPV) possibly contributed to the stable control of SIADH in the patient.

\section{Case Report}

A 69-year-old man with hyponatremia was referred to our hospital. His medical history included type 2 diabetes mellitus (15 years) and chronic pancreatitis. He had a 50-year history of drinking 1-2 units of alcohol and smoking 30 cigarettes per day. His family history was unremarkable. He had noticed malaise and dyspnea at 6 months before his referral. He reported losing $13.5 \mathrm{~kg}$ of body weight in the previous 6 months, despite having a good appetite. He had

\footnotetext{
${ }^{1}$ Department of Internal Medicine, Osaka Red Cross Hospital, Japan, ${ }^{2}$ Department of Diabetes and Endocrinology, Osaka Red Cross Hospital, Japan, ${ }^{3}$ Department of Neurology, Osaka Red Cross Hospital, Japan, ${ }^{4}$ Department of Respiratory Medicine, Osaka Red Cross Hospital, Japan, ${ }^{5}$ Department of Neurology, Tokyo Metropolitan Geriatric Hospital and Institute of Gerontology, Japan and ${ }^{6}$ Department of Neuromuscular Research, National Institute of Neuroscience, National Center of Neurology and Psychiatry, Japan Received for publication December 23, 2015; Accepted for publication August 4, 2016 Correspondence to Dr. Takaaki Murakami, tmurakam@kuhp.kyoto-u.ac.jp
} 
Table 1. Laboratory Results on First Admission to Our Hospital (Day1).

\begin{tabular}{|c|c|c|c|c|c|}
\hline Complete blood count & & $\begin{array}{c}\text { Reference } \\
\text { ranges }\end{array}$ & Hormone & & \\
\hline $\mathrm{WBC}(/ \mu \mathrm{L})$ & 7,670 & $3,500-9,400$ & TSH (IU/mL) & 1.68 & $0.54-4.26$ \\
\hline $\mathrm{RBC}\left(\times 10^{4} / \mu \mathrm{L}\right)$ & 464 & $420-570$ & Free T4 (ng/dL) & 1.35 & $0.71-1.52$ \\
\hline $\mathrm{Hb}(\mathrm{g} / \mathrm{dL})$ & 14.1 & $13-17.5$ & $\mathrm{ACTH}(\mathrm{pg} / \mathrm{mL})$ & 27.3 & $7.2-63.3$ \\
\hline Hematocrit (\%) & 41.9 & $40-52$ & Cortisol $(\mu \mathrm{g} / \mathrm{dL})$ & 12.5 & $6.2-19.4$ \\
\hline Platelet $\left(\times 10^{4} / \mu \mathrm{L}\right)$ & 20.5 & $15-35$ & $\mathrm{GH}(\mathrm{ng} / \mathrm{mL})$ & 0.59 & $0-2.47$ \\
\hline Blood Chemistry & & & IGF-1 (ng/mL) & 81 & $65-209$ \\
\hline $\operatorname{ALB}(\mathrm{g} / \mathrm{dL})$ & 4.8 & $3.7-5.2$ & $\begin{array}{l}\text { Plasma renin activity } \\
(\mathrm{ng} / \mathrm{mL} \cdot \mathrm{h})\end{array}$ & 0.8 & $0.3-2.9$ \\
\hline T-bil (mg/dL) & 0.5 & $0.2-1.0$ & Aldosterone (pg/mL) & 131 & 29.9-159 \\
\hline AST (IU/L) & 18 & $10-40$ & $\operatorname{AVP}(p g / m L)$ & 1.3 & $0-3.8$ \\
\hline ALT (IU/L) & 16 & $4-44$ & & & \\
\hline $\mathrm{CK}(\mathrm{IU} / \mathrm{L})$ & 102 & $56-244$ & Urinalysis & & \\
\hline BUN (mg/dL) & 9.4 & $8-22$ & Urinary sodium $(\mathrm{mEq} / \mathrm{L})$ & 107 & $40-250$ \\
\hline Creatinine (mg/dL) & 0.52 & $0.61-1.04$ & $\begin{array}{l}\text { Urinary potassium } \\
(\mathrm{mEq} / \mathrm{L})\end{array}$ & 39 & $20-60$ \\
\hline Sodium (mEq/L) & 129 & $135-147$ & Urinary chloride $(\mathrm{mEq} / \mathrm{L})$ & 114 & $40-180$ \\
\hline Potassium $(\mathrm{mEq} / \mathrm{L})$ & 4.5 & $3.5-5.0$ & Urinary creatinine $(\mathrm{mg} / \mathrm{dL})$ & 58.4 & \\
\hline Chloride $(\mathrm{mEq} / \mathrm{L})$ & 114 & $98-110$ & $\begin{array}{l}\text { Urinary osmolarity } \\
(\mathrm{mOsm} / \mathrm{kg})\end{array}$ & 519 & \\
\hline Uric acid (mg/dL) & 2.6 & $4.0-7.0$ & & & \\
\hline Plasma & & & & & \\
\hline HbAlc $(\%)$ & 6.3 & $4.7-6.2$ & & & \\
\hline $\begin{array}{l}\text { Plasma Osmolarity } \\
\quad(\mathrm{mOsm} / \mathrm{kg})\end{array}$ & 267 & $275-290$ & & & \\
\hline $\mathrm{BNP}(\mathrm{pg} / \mathrm{mL})$ & 23.7 & $0-18.4$ & & & \\
\hline \multicolumn{6}{|c|}{$\begin{array}{l}\text { WBC: white blood cell count, RBC: red blood cell count, ALB: serum albumin, T-bil: total } \\
\text { bilirubin, AST: aspartate aminotranferase, ALT: alanine aminotranferase, CK: creatine kinase, BUN: } \\
\text { blood urea nitrogen, HbA1c: hemoglobin Alc, BNP: brain natriuretic peptide, TSH: thyroid } \\
\text { stimulating hormone, free T4: free total thyroxine, ACTH: adrenocorticotropic hormone, GH: } \\
\text { growth hormone, IGF-1: insulin-like growth factor 1, AVP: plasma arginine vasopressin }\end{array}$} \\
\hline
\end{tabular}

been taking glimepiride, metformin, and camostat mesilate for several years, and he had started taking vildagliptin and miglitol less than 1 year previously. He consulted his primary care physician 3 months before being referred to our hospital. The laboratory findings at that time showed low serum sodium levels $(130 \mathrm{mEq} / \mathrm{L})$, and he was treated with daily saline infusions. However, at 1 month prior to his referral, his laboratory findings showed the recurrence of low serum sodium levels $(124 \mathrm{mEq} / \mathrm{L})$, and he was admitted to the previous hospital. Cranial magnetic resonance imaging (MRI) and chest computed tomography (CT) showed no remarkable findings, such as emphysematous changes. Abdominal CT showed only chronic pancreatitis. Upper and lower gastrointestinal endoscopy was also performed, but revealed no significant findings. He was discharged after treatment with saline infusion and was referred to our hospital for further investigation.

On admission, the patient (height, $173.8 \mathrm{~cm}$; weight, 57.8 $\mathrm{kg}$; and BMI $19.1 \mathrm{~kg} / \mathrm{m}^{2}$ ) was alert and lean. A physical examination revealed no conjunctival pallor, indicating no anemia. His thyroid was not palpable; neither crackles nor heart murmurs were audible. There were no signs of edema or dehydration. A neurological examination revealed no obvious muscle weakness or any sensory or tendon reflex disorder. Regrettably, we did not examine the patient's brainstemrelated reflexes or the fascicular contraction of the tongue at this time. Chest radiography showed no remarkable lung abnormalities. Laboratory findings (Table 1) showed low se- rum sodium levels $(129 \mathrm{mEq} / \mathrm{L})$, whereas his urinary sodium excretion was relatively high $(107 \mathrm{mEq} / \mathrm{L})$. The patient's ability to concentrate urine was maintained, with a urinary osmolality of $519 \mathrm{mOsm} / \mathrm{kg}$; his serum uric acid levels decreased to $2.6 \mathrm{mg} / \mathrm{dL}$. The endocrinological data showed normal levels of serum thyroid-stimulating hormone, free thyroxine, and adrenocorticotropic hormone. The plasma arginine vasopressin level, as measured by a radioimmunoassay (AVP kit; Yamasa, Chiba, Japan), was relatively high at $1.3 \mathrm{pg} / \mathrm{mL}$, despite a plasma osmolality of $267 \mathrm{mOsm} / \mathrm{kg}$. These findings strongly indicated a diagnosis of SIADH.

Treatment with water restriction was initiated on admission (day 1). We estimated that the patient's water intake at home was over $2,000 \mathrm{~mL} /$ day. We initiated water restriction to $1,200 \mathrm{~mL} /$ day [approximately $20 \mathrm{~mL} / \mathrm{kg}$ /day based on a previous report (6)] because he could not tolerate or follow severe water restriction at that time. His serum sodium level did not increase despite water restriction. Because he had started taking vildagliptin and miglitol less than 1 year previously, we discontinued vildagliptin on day 3 and miglitol on day 6, but his serum sodium concentration did not change. On day 5, we increased the water restriction from 1,200 to $900 \mathrm{~mL} /$ day and started the oral administration of $1.5 \mathrm{~g} \mathrm{NaCl}$ on day 6 , but there was no change in the serum sodium concentration. We therefore changed his water restriction from 900 to $1,200 \mathrm{~mL} /$ day on day 10 and discontinued the oral administration of $\mathrm{NaCl}$, which resulted in no symptoms and the maintenance of his serum sodium con- 


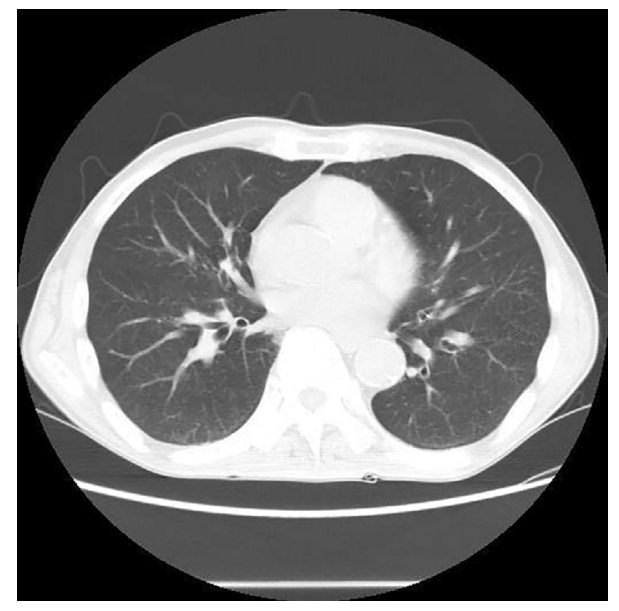

Figure 1. Chest computed tomography (CT) obtained during the patient's first admission to our hospital. CT showed no emphysematous changes or space-occupying lesions.

centration. To determine the cause of SIADH, additional brain MRI, abdominal CT and MRI, and chest CT (Fig. 1) were performed; however, they showed no significant findings. Despite his history of smoking, chest CT showed no emphysematous changes, and no space-occupying lesion was found. Neither hilar lymphadenopathies nor pulmonary inflammatory changes were observed. Although the respiratory function tests showed a decreased vital capacity as a percentage of the predicted value (\%VC) $(69 \%)$ and normal forced expiratory volume in 1 second as a percentage of forced vital capacity $\left(\mathrm{FEV}_{1.0} \%\right)(95 \%)$, he showed no dyspnea after quitting smoking and refused to undergo further investigation in relation to this restrictive respiratory disorder. He was therefore discharged from our hospital on day 16 and followed up by his primary care physician.

He visited his primary care physician 41 days after his discharge (day 57) because of worsening malaise and dyspnea. Because the laboratory findings revealed a recurrence of hyponatremia, he was referred and admitted to our hospital. Following admission to our hospital, he was able to ambulate independently and was alert. A physical examination revealed no prominent changes, with the exception of mild muscle atrophy of the cervical and intercostal muscles as well as the upper extremities. No edema or dehydration was observed. Laboratory findings (Table 2) showed low serum sodium levels $(115 \mathrm{mEq} / \mathrm{L})$ and plasma hyposmolality (252 $\mathrm{mOsm} / \mathrm{kg}$ ); his ability to concentrate urine was maintained. These findings again strongly indicated a diagnosis of SIADH. The patient's clinical course during his second admission is shown in Fig. 2. At first, poor compliance with water restriction was suspected as the cause of his recurrent hyponatremia, but the water restriction had continued at home due to his family's attentiveness. He did not consume alcohol, and his medications had remained the same since the previous hospital discharge. We started strict water restriction on admission (1,200 $\mathrm{mL} /$ day) and recorded the amount of drinking, which revealed that he drank no more than $1,000 \mathrm{~mL} /$ day. On day 60 , we started an infusion of $0.9 \% \mathrm{NaCl}$, but his serum sodium concentration remained as low as $121 \mathrm{mEq} / \mathrm{L}$. The patient and his family had received information about tolvaptan and enthusiastically requested its use. After obtaining patient's written consent according to a previous report (7), the oral administration of tolvaptan was initiated on day 63 at a dose of $7.5 \mathrm{mg}$; the dose selection was based on a previous report (7), and water restriction was not mandatory, as previously reported (8). Subsequently, the patient's serum sodium concentration increased from 120 to $123 \mathrm{mEq} / \mathrm{L}$ in 24 hours. On the morning of day 65, his level of consciousness deteriorated, with a Glasgow Coma Scale score of 11. Central pontine myelinolysis (CPM) due to rapid serum sodium elevation was initially suspected, despite the fact that the patient's serum sodium concentration had not increased very rapidly $(125 \mathrm{mEq} / \mathrm{L}$ on day 65). MRI and CT of the brain showed no significant findings such as typical findings of CPM. Arterial blood gas revealed hypercapnia with respiratory acidosis; we therefore suspected that the cause of his consciousness disturbance was $\mathrm{CO}_{2}$ narcosis. After the initiation of NPPV, his hypercapnia improved, and he became alert (day 66) (Fig. 2). On day 67, he felt feverish, and his blood laboratory data indicated the presence of an inflammatory reaction. He was diagnosed with pneumonia because a chest radiograph showed consolidation of the right lower lung. We initiated antibiotic therapy to treat the patient's pneumonia and NPPV was continued. We discontinued antibiotics on day 74 because of improvement of laboratory data and the improvement of the consolidation on a chest radiograph. Subsequently, his serum sodium level was normalized and maintained within the normal range, even after NPPV, despite the state of inflammation associated with pneumonia, which was followed by tapering and the discontinuation of tolvaptan on day 74 (Fig. 2).

To investigate the cause of the SIADH and/or $\mathrm{CO}_{2}$ narcosis, we retested the patient's respiratory function. The findings indicated the worsening of his \% VC (59\%) and showed that his $\mathrm{FEV}_{1.0} \%$ value was $94.5 \%$. Chest radiographs during the inspiratory and expiratory phases showed bilateral movement of the diaphragm only between one intercostal margin (Fig. 3). A whole-body CT revealed atrophy of the paraspinal muscles in addition to the atrophy of muscles that had been observed on physical examination on the second admission (Fig. 4). The results of spinal MRI and a cerebrospinal fluid examination were not surprising. Considering the possibility of a neuromuscular disease, a careful neurological examination by neurologists revealed positive snout and palmomental reflexes. An electromyogram revealed denervation and reinnervation patterns in the tongue, sternocleidomastoid, deltoid, biceps brachii, and paraspinal muscles. The pathological findings of a biceps brachii muscle biopsy specimen showed neurogenic changes with small to large group atrophy, scattered pyknotic nuclear clumps, and marked fiber type grouping. Based on these findings and the patient's progressive clinical course (Fig. 4), a diagnosis of 
Table 2. Laboratory Results on Second Admission to Our Hospital.

\begin{tabular}{|c|c|c|c|c|c|}
\hline Complete blood count & Day 57 & Day 64 & Hormone & Day 57 & Day 64 \\
\hline $\mathrm{WBC}(/ \mu \mathrm{L})$ & 6,070 & 6,080 & TSH (IU/mL) & 1.40 & - \\
\hline $\mathrm{RBC}\left(\times 10^{4} / \mu \mathrm{L}\right)$ & 456 & 473 & Free T4 (ng/dL) & 1.44 & - \\
\hline $\mathrm{Hb}(\mathrm{g} / \mathrm{dL})$ & 13.9 & 14.4 & $\begin{array}{l}\text { Plasma renin activity } \\
(\mathrm{ng} / \mathrm{mL} \cdot \mathrm{h})\end{array}$ & 1.1 & - \\
\hline Hematocrit (\%) & 39.4 & 42.5 & Aldosterone $(\mathrm{pg} / \mathrm{mL})$ & 215 & - \\
\hline Platelet $\left(\times 10^{4} / \mu \mathrm{L}\right)$ & 16.0 & 19.2 & $\operatorname{AVP}(\mathrm{pg} / \mathrm{mL})$ & 1.7 & - \\
\hline Blood Chemistry & & & Urinalysis & & \\
\hline $\operatorname{ALB}(\mathrm{g} / \mathrm{dL})$ & 5.1 & 5.0 & Urinary sodium $(\mathrm{mEq} / \mathrm{L})$ & 34 & 63 \\
\hline T-bil (mg/dL) & 0.8 & 0.5 & Urinary potassium $(\mathrm{mEq} / \mathrm{L})$ & 26 & 20 \\
\hline AST (IU/L) & 23 & 19 & Urinary chloride $(\mathrm{mEq} / \mathrm{L})$ & 44 & 86 \\
\hline ALT (IU/L) & 18 & 22 & Urinary creatinine $(\mathrm{mg} / \mathrm{dL})$ & 44.26 & 58.87 \\
\hline BUN (mg/dL) & 9.9 & 12.8 & $\begin{array}{l}\text { Urinary osmolarity } \\
(\mathrm{mOsm} / \mathrm{kg})\end{array}$ & 599 & - \\
\hline Creatinine (mg/dL) & 0.50 & 0.46 & Arterial blood gas & $\begin{array}{l}\text { room } \\
\text { air }\end{array}$ & $\begin{array}{c}32 \% \\
\text { Oxygen }\end{array}$ \\
\hline Sodium (mEq/L) & 115 & 125 & $\mathrm{pH}$ & 7.351 & 7.254 \\
\hline Potassium $(\mathrm{mEq} / \mathrm{L})$ & 4.9 & 4.9 & $\mathrm{PCO}_{2}(\mathrm{mmHg})$ & 71.5 & 109.7 \\
\hline Chloride $(\mathrm{mEq} / \mathrm{L})$ & 73 & 78 & $\mathrm{PO}_{2}(\mathrm{mmHg})$ & 60.1 & 82.9 \\
\hline Uric acid (mg/dL) & 1.8 & 1.5 & $\mathrm{HCO}_{3}(\mathrm{mmoL} / \mathrm{L})$ & 38.7 & 47.5 \\
\hline Plasma & & & $\mathrm{BE}(\mathrm{mmoL} / \mathrm{L})$ & 10.2 & 14.7 \\
\hline HbAlc $(\%)$ & 7.0 & - & & & \\
\hline $\begin{array}{l}\text { Plasma Osmolarity } \\
\quad(\mathrm{mOsm} / \mathrm{kg})\end{array}$ & 252 & 278 & & & \\
\hline $\mathrm{BNP}(\mathrm{pg} / \mathrm{mL})$ & 54.7 & - & & & \\
\hline
\end{tabular}

WBC: white blood cell count, RBC: red blood cell count, ALB: serum albumin, T-bil: total bilirubin, AST: aspartate aminotranferase, ALT: alanine aminotranferase, BUN: blood urea nitrogen, HbA1c: hemoglobin Alc, BNP: brain natriuretic peptide, TSH: thyroid stimulating hormone, free T4: free total thyroxine, AVP: plasma arginine vasopressin, $\mathrm{PCO}_{2}$ : partial pressure of carbon dioxide, $\mathrm{PO}_{2}$ : partial pressure oxygen, $\mathrm{HCO}_{3}$ : bicarbonate, $\mathrm{BE}$ : base excess

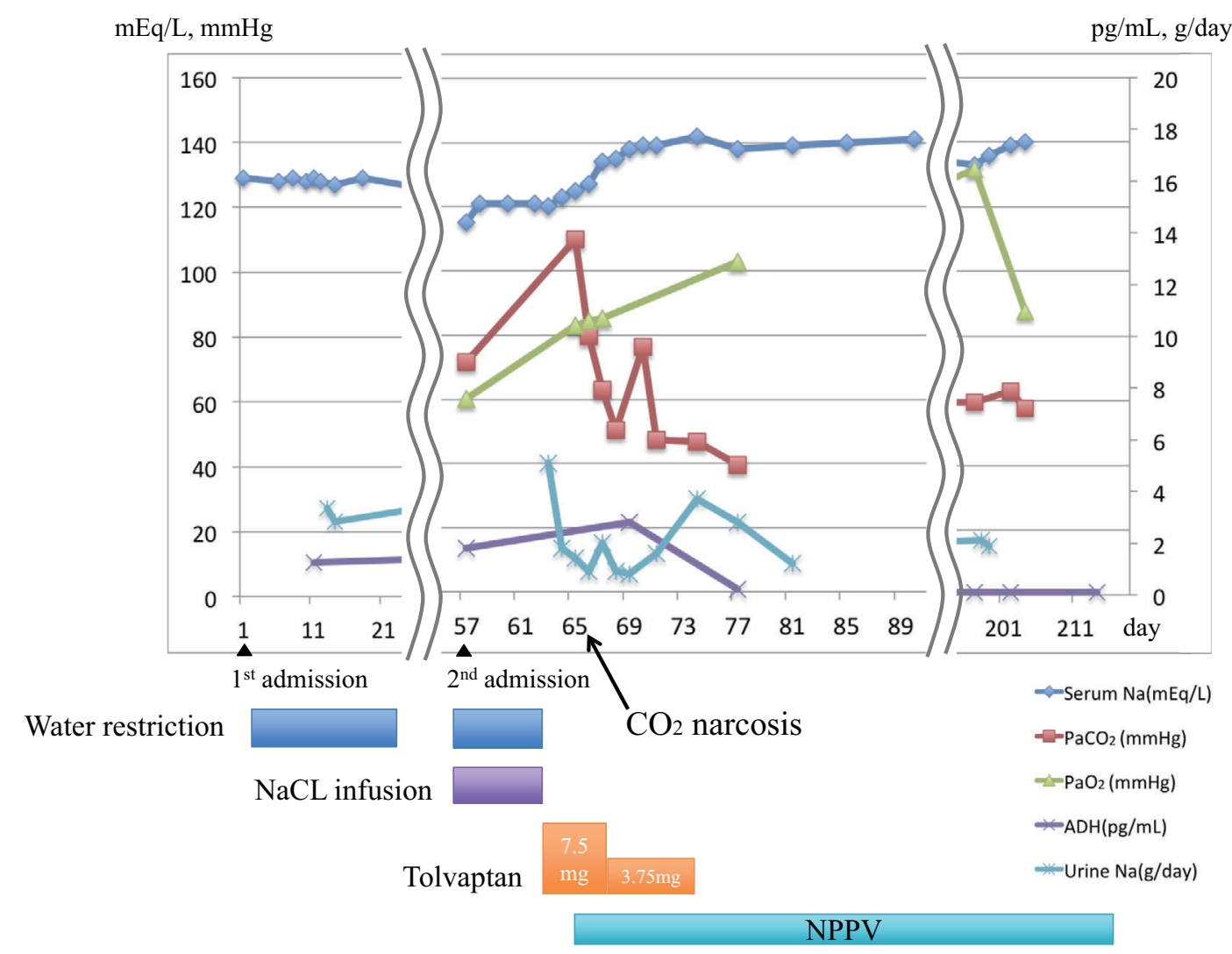

Figure 2. The clinical course, laboratory data, and treatment of the present case. $\mathrm{CO}_{2}$ : carbon dioxide, NPPV: non-invasive positive pressure ventilation

ALS was established.

The patient was discharged on day 90, and NPPV was continued during sleep. Although he started showing muscle atrophy of his lower limbs (day 197), his serum sodium 


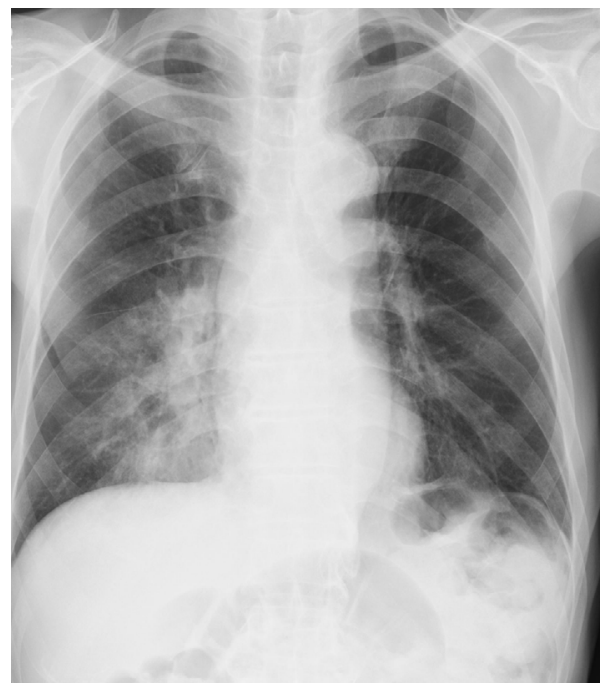

Inspiratory phase

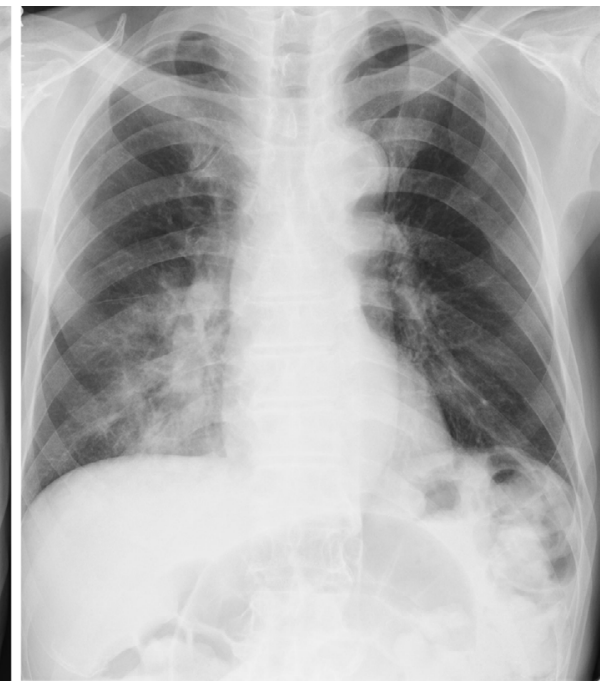

Expiratory phase

Figure 3. Chest radiographs of the inspiratory and expiratory phases of breathing. Bilateral movement of the diaphragm was only observed between one intercostal margin.

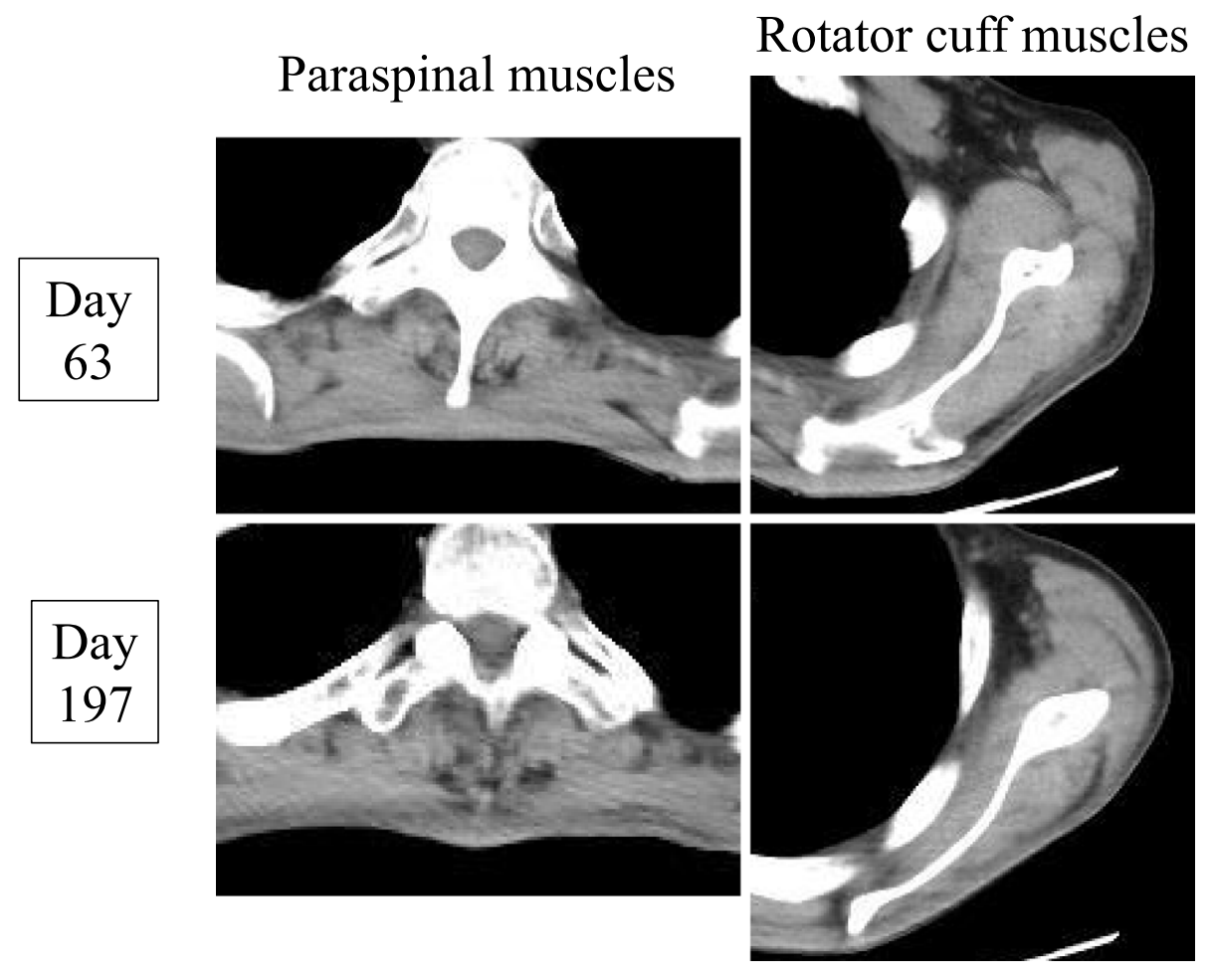

Figure 4. Progressive atrophy of the paraspinal and rotator cuff muscles.

concentration was maintained at $137 \mathrm{mEq} / \mathrm{L}$ (day 124) and $139 \mathrm{mEq} / \mathrm{L}$ (day 197). After NPPV, the patient's serum $\mathrm{ADH}$ levels were maintained at a low level $(<0.8 \mathrm{pg} / \mathrm{mL})$, and his urinary sodium excretion decreased (Fig. 2).

\section{Discussion}

The finding of SIADH accompanied by ALS is very rare (5). To the best of our knowledge, only seven cases of SIADH accompanied by ALS, including our case, have been reported $(5,9-12)$. Although ALS is clinically progressive and serious, it is both a rare and unfamiliar disease to primary care physicians and endocrinologists, who are likely to be primarily in charge of patients with hyponatremia in the clinical setting. We therefore emphasize the clinical importance of the early recognition of ALS as a possible cause of SIADH. Regrettably, in the present case, a delayed recognition of this possibility may have contributed to $\mathrm{CO}_{2}$ narcosis; however, the patient had presented with weight loss and restrictive ventilatory impairment. Moreover, four out of the seven reported cases of SIADH accompanied by ALS presented with hyponatremia almost concomitantly with the di- 
agnosis of ALS. The remaining three cases were diagnosed with ALS prior to the occurrence of hyponatremia (5, 9-12). This suggests that we should recognize ALS as a possible cause of SIADH. At the same time, we should closely investigate the neurological findings when we encounter a patient with newly diagnosed SIADH.

In this case, the laboratory and physical findings during a sequence of admissions were in concordance with the criteria for SIADH (13). A highly concentrated $\mathrm{NaCl}$ infusion was not initiated because, aside from $\mathrm{CO}_{2}$ narcosis, our patient showed only chronic hyponatremia and full consciousness (14). Tolvaptan was used for the treatment of SIADH because of his and his family's strong request as well as the clinical usefulness of this agent. Tolvaptan is one of the most effective drugs for treating hyponatremia in patients with SIADH (8). It is currently available in the United States and Europe, but not in Japan; however, its clinical use in Japan has been reported (7). We therefore carefully used tolvaptan in accordance with the previous reports, which promptly increased the patient's serum sodium levels (Fig. 2). In addition, the serum sodium concentration was stable even without tolvaptan and water restriction, which may indicate that NPPV could contribute to the treatment of hyponatremia in SIADH with ALS.

The underlying mechanism of the association between SIADH and ALS remains controversial. The following mechanisms have been hypothesized: 1) hypoxia and hypercapnia, 2) an intrathoracic circulation dysfunction, and 3) emotional factors and physical stress $(5,9-12)$. First, hypoxia can cause the constriction of the pulmonary vessels and decrease the venous return to the left atrium. Furthermore, it can stimulate the hypothalamus directly or indirectly via the carotid baroreceptors. At the same time, hypercapnia can stimulate ADH secretion via the baroreceptors or by inducing acidosis (15). Second, dysfunction of the intrathoracic circulation due to the atrophy of the respiratory muscles may decrease venous return to the left atrium (16). Third, emotional factors and physical stress can influence ADH secretion (17). In all but one (12) of the previous reports $(5,9-11)$, the patients showed a restrictive ventilatory defect and hypercapnia. The one exception was described as a drug-induced case (12). Hypoxia was not observed at the time of SIADH diagnosis in any of the cases $(5,9-12)$. In our case, hypercapnia without hypoxia was observed. Taken together, chronic hypercapnia due to respiratory muscle atrophy may have been the cause of SIADH in our case.

Moreover, although NPPV may increase the intrathoracic pressure and promote $\mathrm{ADH}$ secretion via the intrathoracic volume receptors, which could lead to the deterioration of SIADH, NPPV contributed to the management of SIADH in our case. Because this favorable effect of mechanical ventilation in ALS-associated SIADH was reported in another study (11), we hypothesized that the hypercapnia and intrathoracic circulatory changes were responsible for the development of SIADH in our patient.

In addition, in the present case, our patient developed pneumonia after NPPV. As previously reported, inflammatory cytokines, such as interleukin (IL) $1 \beta$ and IL-6, are involved in the development of hyponatremia due to $\mathrm{ADH}$ secretion (18). IL-1 $\beta$ stimulates both the central and peripheral release of vasopressin, and IL-6 induces the activation of AVP neurons $(19,20)$. However, inflammatory cytokines may not have significantly contributed to the development of SIADH in our case because the patient did not present with pneumonia at the time of the initial diagnosis of SIADH. Moreover, his serum sodium levels did not decrease at any point while he had pneumonia.

Finally, his hypercapnia seemed to deteriorate on the second day of tolvaptan treatment (Fig. 2). It is suggested that the effect of inhibition of ADH by tolvaptan leads to a decrease in the pulmonary blood flow and contributes to the rapid worsening of hypercapnia. However, the exact evaluation of pulmonary blood flow was challenging in our case. Thus, we should note that tolvaptan may cause a rapid decrease in the pulmonary blood flow in some cases when SIADH occurs concomitantly with ALS. At the same time, we might suggest the possibility of the rapid worsening of hypercapnia in patients with COPD. In such patients, the pulmonary vascular bed and pulmonary blood flow may be decreased to a similar extent to that which is observed in ALS-associated SIADH (21).

In summary, we reported a rare case of ALS-associated SIADH. Our patient presented with disturbed consciousness due to $\mathrm{CO}_{2}$ narcosis after sustained hyponatremia, which led to the diagnosis of ALS. We therefore emphasize the clinical importance of the early recognition of ALS as a possible cause of SIADH. Moreover, NPPV may contribute to a stable control of SIADH in such cases.

The authors state that they have no Conflict of Interest (COI).

Yui Inoue and Takaaki Murakami contributed equally to this work.

\section{References}

1. Upadhyay A, Jaber BL, Madias NE. Incidence and prevalence of hyponatremia. Am J Med 119: S30-S35, 2006.

2. Ellison DH, Berl T. Clinical practice. The syndrome of inappropriate antidiuresis. N Engl J Med 356: 2064-2072, 2007.

3. Clayton JA, Le Jeune IR, Hall IP. Severe hyponatremia in medical in-patients: aetiology, assessment and outcome. QJM 99: 505-511, 2006.

4. Hannon MJ, Thompson CJ. The syndrome of inappropriate antidiuretic hormone: prevalence, causes and consequences. Eur J Endocrinol 162: S5-S12, 2010.

5. Koyama S, Aizawa H, Haga T, Nakatani-Enomoto S, Kikuchi K. An autopsy case of amyotrophic lateral sclerosis accompanied by syndrome of inappropriate secretion of antidiuretic hormone. Intern Med 41: 395-397, 2002.

6. Diagnosis and treatment of SIADH proposed by research committee of dysfunction of diencephalon and pituitary gland function supported by Ministry of Health, Labour and Welfare, Japan. 2010. Available from: http://rhhd.info/pdf/001008.pdf (in Japa- 
nese).

7. Yamashita T, Yoshida M, Yamada H, et al. Prompt efficacy of tolvaptan in treating hyponatremia of syndrome of inappropriate secretion of antidiuretic hormone (SIADH) closely associated with rupture of a gastric artery aneurysm. Intern Med 53: 845-849, 2014.

8. Schrier RW, Gross P, Gheorghiade M, et al. Tolvaptan, a selective oral vasopressin V2-receptor antagonist, for hyponatremia. N Engl J Med 355: 2099-2112, 2006.

9. Arakawa K, Nishio T, Sunohara N. Two cases of MND/ALS developing the syndrome of inappropriate secretion of antidiuretic hormone. Acta Neurol Scand 96: 262-265, 1997.

10. Yoshida Y, Kato B, Mizushima Y, et al. Syndrome of inappropriate secretion of antidiuretic hormone associated with amyotrophic lateral sclerosis in respiratory failure. Respirology 4: 185-187, 1999.

11. Motoo Y, Ohta H, Okai T, Sawabu N. Amyotrophic lateral sclerosis associated with the syndrome of inappropriate secretion of antidiuretic hormone. Intern Med 31: 1023-1025, 1992.

12. Nakazato Y, Takei K, Yamazato M, Tamura N, Shimazu K. A case of amyotrophic lateral sclerosis with SIADH and throbbing headache induced by selective serotonin reuptake inhibitor. Rinsho Shinkeigaku (Clinical Neurology) 42: 48-50, 2002 (in Japanese, Abstract in English).

13. Schwartz WB, Bennett W, Curelop S, Bartter FC. A syndrome of renal sodium loss and hyponatremia probably resulting from inappropriate secretion of antidiuretic hormone. Am J Med 23: 529542, 1957.

14. Verbalis JG, Goldsmith SR, Greenberg A, et al. Diagnosis, evalu- ation, and treatment of hyponatremia: expert panel recommendations. Am J Med 126: S1-S42, 2013.

15. Rose CE Jr, Anderson RJ, Carey RM. Antidiuresis and vasopressin release with hypoxemia and hypercapnia in conscious dogs. Am J Physiol 247: R127-R134, 1984.

16. Kumar A, Pontoppidan H, Baratz RA, Laver MB. Inappropriate response to increased plasma $\mathrm{ADH}$ during mechanical ventilation in acute respiratory failure. Anesthesiology 40: 215-221, 1974.

17. Sørensen JB, Andersen MK, Hansen HH. Syndrome of inappropriate secretion of antidiuretic hormone (SIADH) in malignant disease. J Intern Med 238: 97-110, 1995.

18. Swart RM, Hoorn EJ, Betjes MG, Zietse R. Hyponatreia and inflammation: the emerging role of interleukin-6 in osmoregulation. Nephron Physiol 118: 45-51, 2011.

19. Landgraf R, Neumann I, Holsboer F, Pittman QJ. Interleukin-1 stimulates both central and peripheral release of vasopressin and oxytocin in the rat. Eur J Neurosci 7: 592-598, 1995.

20. Palin K, Moreau ML, Sauvant J, et al. Interleukin-6 activates arginine vasopressin neurons in the supraoptic nucleus during immune challenge in rats. Am J Physiol Endocrinol Metab 296: E1289-E1299, 2009.

21. Voelkel NF, Gomez-Arroyo J, Mizuno S. COPD/emphysema: the vascular story. Pulm Circ 1: 320-326, 2011.

The Internal Medicine is an Open Access article distributed under the Creative Commons Attribution-NonCommercial-NoDerivatives 4.0 International License. To view the details of this license, please visit (https://creativecommons.org/licenses/ by-nc-nd/4.0/).

(C) 2017 The Japanese Society of Internal Medicine http://www.naika.or.jp/imonline/index.html 